\title{
Trauma and the Zero Process: Clinical Illustrations
}

\author{
Joseph Fernando \\ Toronto Institute of Psychoanalysis, Toronto, Canada
}

The aim of this article is to explore the basic mental mechanisms operative during and after trauma. To facilitate this exploration, details from the therapy of two traumatized are presented. These cases demonstrate concretely how a traumatic process is set in motion by overwhelming of the usual protective filtering mechanisms of the mind. This happens when too much that is too upsetting and too unexpected is experienced too quickly. Being unable to process the incoming stimulation in the usual ways, many higher level mental functions, such as integration, differentiation, abstraction, thought, and symbolic processes are shut down. This shut down interferes with the formation of regular long term memories. Instead what is left in the aftermath of trauma are unintegrated bits and pieces of perception, feeling, and action intention which act much more as a present experience or future expectation than as a regular memory. This particular form of mental functioning that follows upon trauma I have conceptualized as the zero process. Clinical aspects of the two cases are used to illustrate characteristics of zero process memories. Triggering of repetitive reliving, and the formation of conversion symptoms based on concrete zero process body memories from the trauma are discussed and illustrated by clinical material.

Psychoanalysis 2018;29(3):37-45

KEY WORDS: Trauma $\cdot$ Zero process $\cdot$ Traumatic process.

Received: March 26, 2018 Accepted: May 1, 2018

Address for correspondence: Joseph Fernando, Mpsy, MD

Toronto Institute of Psychoanalysis, 40 St. Clair Ave. East, Toronto, ON M4T 1M9, Canada

Tel: +1-416-975-9147, E-mail: jfernsympatico@gmail.com

In this paper I will present some clinical material from two patients of mine, as illustrations of the nature of the traumatic process and the form of mental functioning that is left over after trauma, which I have conceptualized as the zero process. In the second paper of this series, I will go into the the theory of the zero process in more detail.

A young girl is at the dinner table with her father and two siblings. She is only four and a half, the two siblings are younger. She has had a very busy and demanding young life. Two younger siblings were born, who took her mother's attention away. At about age three, she developed croup, and was kept in a tent in hospital. She remembers breaking out of it and wandering the hospital corridor till a nurse found her. When her mother was pregnant with the youngest, cancer was discovered. She was treated, but over the next year and a half, deteriorated and finally ended up in hospital, thin and wasting away. The young girl visited her there. She remembered lying beside her mother on the hospital bed, facing away from her and looking at a figurine of an animal that was on the bedside table. This day at dinner her father, with

This is an Open Access article distributed under the terms of the Creative Commons Attribution Non-Commercial License (https://creativecommons.org/licenses/by-nc/4.0) which permits unrestricted non-commercial use, distribution, and reproduction in any medium, provided the original work is properly cited. the youngest on his lap, tells the children that their mother is not going to be coming home. He says that they will have to stick together as a family. As he says this, the young girl has a powerful physical feeling, that she has been punched in the stomach. She cannot breath or eat. And a darkness, experienced not symbolically but actually, as darkness, enters into her through her belly.

This young girl eventually, as an adult, came to see me for help with her relationship, and certain anxieties. She told me about what had happened to her mother. She felt this may have had something to do with her difficulties, and had made some connections between this past event and her present difficulties, at least intellectually. There is much to be said about the events both before and after this pivotal moment. I would like first to concentrate on the moment itself. My patient, Cordelia, did not go very far into the details of the incident when she would mention it, but would merely recount what her father had said and how bad she had felt. The incident was not repressed, but rather Cordelia avoided thinking of it. The details I mentioned only emerged with repeated retelling. In some instances of trauma, the avoidance can be almost total, but in her case it seemed to be directed mainly at going into too much detail, at the emotional intensity, and at the connections of the incident to other things. One connection she did make right from the start was that each of her long term 
relationships had lasted about 4 years, at which time she felt a powerful need or urge to leave.

Cordelia was in psychotherapy, twice a week for most of the time, sitting up. Lets look at a few sessions a couple of years into her therapy: she came into a session and started talking of how she was quite angry at her husband for not doing various things she thought he should, to take care of his recovery from a serious illness he had had. She was not a pushy person in general, she said (and her behaviour in therapy bore this out), but she was pushy in relation to people's health (she had in fact made recommendations to me as well). People were never doing enough to take care of their health, and she would get angry at them for resisting her advice. She remembers this going on at least from the age of 20, when she began pushing remedies on her somewhat reluctant father. I said something about whether there is some pleasure as she does this. "It doesn't feel good when I'm doing it," Cordelia said with some feeling, and a look that showed distaste or even disgust. "I get a funny feeling in my stomach, when I think of doing it. Like with my mother." (We both knew she was referring to the incident when she was told about her mother's death.)

"If you stick with that feeling, what else comes up?"

"Its like a black hole in my stomach, that would suck everything into it." she seemed to visibly shudder as she described this. "It feels like death itself. But maybe its my aggression as well. I think of my fear of intruders. They seem like that same black hole-but maybe they are really my own aggression."

"Come back to haunt you, and attack you."

"It really does seem like it. I think of the dream of the murderer, at night. (A dream dreamt at the start of therapy, of a murderer killing people and burying them, at night, while the patient, in fear, tried to hide.) Was it me?" She talked of her aggression.

As we talked of this, Cordelia became somewhat overwhelmed, looking shaken. It was the end of the session, and I asked if she was O.K. to leave. She said she would be fine, but she was a bit surprised by the strength of the feelings.

At the next session, a week later, Cordelia returned to the need to save people. "I pushed S (her stepmother) to give my father some different remedies for his health problems. She said he was O.K. I was about to push some more, but then I held myself back. I tried to let it go. I didn't say anything more, but it was hard."

She then brought up the incident when she was told of her mother's death. She repeated what was said by her father, that she had described previously, that they had to stick together as a family. "I lost my appetite. I may have had food in my mouth but I don't think I could eat any more. Its like I could not swallow; like my food was dry. Time stopped. It was like a black hole. It was like I died, in that moment. For that moment. A frozen moment with a black hole. Like the intruder in the house, it's dark like the night when the intruder comes in. Is the intruder maybe death itself?"

There was a silence, and I said, "it all went inside you."

"Maybe if I kept it inside me, I could stop time."

"And save your mother."

Cordelia was crying through the last part of this exchange, and said, as she had tears in her eyes, that she was not sure why the tears were coming now. She would often start to cry, even at earlier times when we had talked about this fateful night. This may seem unsurprising, to cry as one talked of hearing of the death of one's mother. But the crying would come somewhat unbidden and often surprise Cordelia. It seemed at times to descend upon her, rather than grow out of an integrated retelling of a story. It could gain in intensity quite suddenly, but also disappear quickly.

At the next session, Cordelia started by complaining that her husband had been driving her crazy, by his controlling, micromanaging behaviour in the lead up to a party they were hosting. A friend had been also talking to her about these negative attributes, and about how he could be quite mean when he got like this. Cordelia felt the need to intervene to damp down these criticisms, and jump to her husband's defence, but she found herself not only holding back but actually taking in what the person was saying, non defensively. She then recounted a dream she had had the night before. "I had something from the past that I had hidden in a wall. Cut up body parts, from a murder I had committed. I felt no guilt, but just worry that I would be found out. But really I had no really strong feelings of any sort." She thought that this related to something that suddenly struck her, that we have always talked of her pain, loss etc at her mother's death, but she was thinking that maybe she did not want to keep her alive, that she wanted to kill her and felt O.K. about it, not guilty, she speculates. She remembers her husband being unpleasant to her. As she says this, she quickly finds reasons that she had brought his harsh words on herself. I point out that she has quickly tried to take on responsibility. Cordelia notices how she did this, as she often does. But then she did it again, trying to figure out ways to behave so people would not get upset at her. She is then led to talk of her time in the crib in the hospital, when she had croup, trying to claw her way out. (As she remembers it there was some kind of mesh over the crib.) She remembers that this was when she was about age 3 , and how scared she was. I point out this maybe a source of the dreams of being buried, by the psychopathic murderer, that she had especially at the beginning of therapy. Cordelia is quite struck by this, especially that she had never thought about it before. 
I note that this was an illness that she had suffered, which she may have wondered about, a little later, with her mom being in hospital. The other times the mother went to hospital, she came back with a baby. Then she went in for something else, on and off, and then was there for the last few months of her life. Hospitals had played quite a large part in her early life, I said, and she nodded.

In the next three sessions, Cordelia had dreams and experiences, all of which led back to the element of surprise. She dreamt that she was living with a past boyfriend; they were together and it seemed really solid. But then he calls her and says, "instead of being here for dinner, why don't you just stop by for lunch?" Cordelia went downstairs to tell her father and stepmother, and saw coffee on the wall, making a mess. It was devastating for Cordelia, this going from one extreme to the other. She thought the relationship was solid and serious, and all of a sudden it wasn't. I connected this to unexpectedly hearing of her mother's death. She noted that she left this boyfriend at four years into the relationship. She had felt an urgent need to get out of the relationship, as if she were trapped and would die in it. But soon after she, to the surprise of her boyfriend, announced that she was leaving, she herself felt bereft, alone and desperate to get back to him. But as she went back and forth like this, unsure, her boyfriend moved on. Later in the session we discussed adolescence, where longing for her mother and father reappeared, as did her anger, enacted with her stepmother especially. "All I wanted was love," she said. A dream in the next session was quite startling: "I was standing there, an attack dog hits the ground, like it was falling from the sky. Its a pit bull type of attack dog that runs at me, and I take a breath in, a gasp, and wake up. I was scared. It was the gasp I really remember, as the dog jumped at me." She wondered about her own aggression, and if this aggression was embodied in the dog. The gasp reminded her of when she was told of her mother's death, a punch in the stomach. She had just heard of a pit bull attack in which the dog had come from the neighbour's back yard, and had killed a woman in her own back yard. Later in the session, there were memories of her mother with her back turned to her, and examples of how angry Cordelia can get when she is not listened to. In the session after this, Cordelia recounted another dream, from the previous night: "I was travelling along with colleagues when all of a sudden, in our path was - there were alligators. It was like a normal activity, and then an emergency-even though we were walking it was also like we were swimming, the alligators were coming at us, and then a piranha was in my face as I was swimming. The presence of the alligators was heavy, menacing, maybe related to anger. Then there were three men; one was Mat Damon. I had gotten myself a treat, a coffee and treat, and they said, "why didn't you get something for us, after all we have been through." There was even more to this long dream. She thought of oral aggression. Then of the fact that she was attacked by a work customer, when she had made some rather mild inquiries about some issues they were dealing with. He got really very angry and biting right out of the blue. As we look at this she finds all sorts of reasons why its really her fault, how she has to find better ways of asking for things, or be more tolerant of people's reactions. But she knows that he is a "hot head", and it does seem that his attack was out of the blue.

\section{Lack of Preparedness, and Being Overwhelmed}

One specific characteristic that appeared again and again in relation to Cordelia being told about her mother's death, was the suddenness of what happened. From the earliest historical descriptions on, this aspect of trauma has been stressed. Being taken by surprise is not just related to time, however, but also to expectation. And expectation is related to our models, both immediate and more general, of the world. So we could say an event has the possibility of becoming traumatic if it comes on so suddenly and/or is so beyond the regular expectations of the person, that they cannot quickly assimilate it. Of course surprise birthday parties can have these characteristics, and yet are usually not traumatic. Yet, if the surprise party is truly unexpected, if for instance the person has never had one, and never expected to, then they not only will not assimilate the event right away, but may seem in a bit of a state of shock, and keep repeating, "I can't believe it, I still just can't believe that this is happening." What this demonstrates is that there are characteristics of what we call trauma that can be separated out from, or experienced separately from, other aspects, and that it is usually only when a number of these aspects occur together that we use the term trauma. The other thing that is needs to be added to surprise to make it traumatic is usually fear or fright or some other extreme negative affect. The specific characteristic that the surprise birthday party isolates and demonstrates is the one of not being able to assimilate the incoming sensory input into one's usual model of the world, and the disruption that this can cause. By the very fact that they disrupt it, these sorts of happenings show us that what we take as our immediate experience is the product of a good deal of working over and assimilation of sensory input.

Cordelia had not been told much about her mother's illness, and certainly had not been told that she was dying. Her father and her mother's parents seem to have been completely overwhelmed by what was happening. It's likely that they were also trying to spare the children upset, as can be seen by their behaviour after the mother's death, of not taking them to 
the funeral. This is not to say that Cordelia would not have had her suspicions, but they would not have been made explicit in her mind, would have been confused with fantasies, and would have been pushed aside and denied. Let's imagine that her father and maternal grandparents had told her, in smaller doses, some of the very upsetting news that they were getting. She would almost certainly have been more overtly upset than she was at hearing the news of her mother's death from her father. She would have been scared, cried, had questions, and had trouble sleeping. What if her mother had told her that she was dying when she visited her in the hospital? It's hard to imagine a more upsetting situation. While the immediate upset would have been much worse, the long term consequences would almost certainly have been less severe, especially if Cordelia had not only been told these unpleasant truths but been then encouraged to talk about her reactions and share her feelings. But even in a less than ideal version of this, the worst consequences would most likely have been averted.

We might say, when it comes to protecting oneself from being traumatized, that readiness is all. Not every surprise, not every reality which is not part of our expectations, is traumatic. At a slower pace, and in smaller doses, they will lead to some level of emotional upset, but not to trauma. (Certain basic therapeutic techniques are based on this fact.) Emotional upset, even serious emotional upset, is not the same as trauma. In fact in certain ways it is the opposite of trauma, at least in the sense that higher level ego functions are still online. Frustration, upset, and upheaval usually spur adaptation and growth, while trauma brings these to a halt. Freud (1920) noted that the development of anxiety seemed protective against traumatic neurosis. This is not immediately obvious, since in situations such as Cordelia's father telling her that her mother was not coming home, she describes an intense reaction. She felt punched in the stomach, she could not swallow her food, and she felt a terrible black hole entering her. It is not always easy to tell from a description like this whether the incident has been truly traumatic or not. It is the chronic changes in her way of experiencing her body and the world that are the clues that something beyond upset was going on.

Early descriptions of trauma emphasized the inability to integrate or accommodate the experience into existing memory schemes or models. Van Der Kolk and Van Der Hart (1995) describe Pierre Janet's views, expressed in the later half of the 19th century: trauma occurs when an incident is too far outside the experiences of the person, so that its memory is never integrated, and actions and feelings that would have been appropriate to the situation are not performed or felt. Symptoms involved versions of the truncated actions and feelings. (We could think of Cordelia trying desperately to "save" any sick person around her.) Therapy involved putting the person in imagination back into the situation and getting them to perform the aborted action, so that the incident and the memory of it could be completed. Until and unless this was done, the incident lived a life split off, or dissociated, from the rest of the person's life and memories. Breuer and Freud (1895) presented a somewhat similar description, stressing strangulate affects.

From this point, Freud took a different fork in the road, going on to emphasize defences and internal emotional conflicts over external overwhelming and dissociation, developing the methods of free association and interpretation, and making his monumental discoveries of childhood sexuality, the Oedipus complex, transference, repression, and the primary process. One of the reasons I chose Cordelia as an example is that some of her symptoms are the sort that Freud and Breuer first described, and they show us how such symptoms can be investigated and analyzed in two directions: towards trauma and dissociation, and towards drive conflicts and repression. In this we can retrace some of the footsteps of history in her therapy. In his later foray into trauma, Freud (1920) added a mechanistic set of concepts to the earlier ideas. He posited a stimulus barrier in the mind, which protected it from being overwhelmed by external stimuli, and he conceptualized trauma as involving the mind being presented with more external stimulation than it can handle, which breaks through this stimulus barrier. When this happens, the usual ways of processing and mastering stimuli are knocked out of commission. This is why upset is the opposite of trauma-to feel upset, you need a whole set of ego functions to produce and become aware of the feelings, while trauma begins at the point at which these ego functions shut down. It begins at a point beyond upset. The person will often describe feeling "numb", as well as having strange changes in their body awareness and perceptions. These are the outward, conscious, signs of the shutting down of various functions, such as the integrative function, that usually construct, quite silently and quickly, our present experience. We see it very well in the incident when Cordelia is told of her mother's death. Suddenly, something seems to give way, and everything is different. She experiences the punch in the stomach and invasion by fear and aggression and loss much more concretely and physically than would normally be the case with something that was merely upsetting. Here we see the partial loss of a number of ego functions-symbolizing and thinking processes-which now are unavailable, as reality assails her physically.

As a preliminary working definition, we could say that trauma involves being faced too quickly with too much that is terrifying, leading to a shutting down of the usual way we process reality. 


\section{Triggers, Repetitions, and Conversion Symptoms}

A number of things could trigger reactions in Cordelia related to her trauma. There is the example of a customer unexpectedly getting angry, attacking her, and saying he did not want her business. She became quite panicked, much more than the actual situation demanded. She felt "like I was a little boat, cut lose from the mother ship." She made this comment without consciously meaning to refer to her actual mother, and only noticed the reference later. It might seem possible that these sorts of triggering reactions, or at least their intensity and frequency, was a product of the therapy, and of our work on her trauma. I wondered about this myself. But as we delved into both the trauma and Cordelia's life before therapy, it became clear that the largest part of her reactions were not a product of our work. In small ways and large in all of her relationships, she was triggered to re-experience aspects the trauma. One very large way, which I described above, in relation to a dream, was feeling compelled to leave relationships at the four year mark, without knowing why. Another example of the smaller triggering was when she heard of an accident in the city in which a car had been speeding and had gone out of control, seriously injuring three thirteen year olds who had been walking on the sidewalk. She mentioned hearing about this and was quite shaken. "How will the parents find out?" was her first thought. "They wouldn't have any I.D. on them. The parents won't know till they don't come home." Again, it was only after we reflected on this, that she saw the similarity to what her father had said about her mother not coming home. She said her upset was because she was picturing what the parents would be feeling when they first realized that their child was dead. Again, surely a revival of her own experience at age four.

Cordelia developed persistent stomach aches when going to school, beginning in the early elementary school years. Investigations could not find a cause. When she was a little older, one of the pains turned out to be appendicitis, and she was taken to hospital for an operation. "Before the operation I was sure I would die, and that no one could help me. None of them had any power to help me, so I asked the highest power, God, to help." The operation went well. In her early 20s Cordelia developed pains that traditional medicine was not able to help her with. One clinician had not only misdiagnosed her but said there was nothing that could be done to cure her. A couple of years later abdominal symptoms of different sorts returned. Since then she had tried all sorts of remedies both within and outside of mainstream medicine. She was losing weight when I saw her, and often would not feel like eating. She did not have the body image distortion or constant preoccupation with food and weight of someone with classical anorexia nervosa.

At one point, she was sure she had colon cancer and would die. A colonoscopy found nothing. She was pleased and surprised by this, and even more surprised by other feelings that came from this knowledge that she was not dying. She became sad and started crying. With this emotional release, the belly discomfort disappeared. It came back again later, and on other occasions there was this very interesting back and forth, with stomach symptoms disappearing as she became sad and cried, and then reappearing later. The anxious certainty that she was dying contained her upset about her mother's death, as well as expressing a powerful identification with her mother, as she was dying. When she was told that she was not, this feeling seemed to have nowhere else to go, and came out directly as sadness. When she cried, and especially as she also linked it to her mother, her belly discomfort disappeared. It was this sort of evidence that led Breuer and Freud (1895) to form their theory of traumatic affect that had been strangulated and unexpressed becoming converted into physical symptoms. A reaction like this does not mean that the symptom has no physical cause, as conversions often chose real pains to jump onto. This is what Breuer and Freud called somatic compliance. Often the physical cause will be a transitory one. When the emotion has jumped onto the symptom, the emotional cause maintains it once the physical cause is no more.

Let me go into a little bit more detail about another of Cordelia's conversion symptoms. She came in one session with a very painful right side. She had almost been unable to come to the appointment, she said. There were pains up her arm, a painful contracture of her hand, and vague pains going further down that side of her body. These later were hard to pin down exactly, and the complex of areas and symptoms were hard to make sense of physically, meaning we could not see how specific nerve, or spinal, or brain related problems could lead to these symptoms. The whole story of how the symptoms had formed only emerged over a number of sessions and even months later, but in this session she talked of the pain, which led to her crying, again a bit surprisingly to her, which led me to wonder about sadness leading to the pain. What she remembered was not sadness but that she had, the day before, been quite angry, fuming in fact, at her husband. Then this anger had disappeared, and the pain and muscle spasm of the hand had started. It had worsened through the night, and she had woken up in extreme pain. She only now made the connection between the disappearance of her anger and the physical symptom, which made her wonder if it was like wanting to hit him, to hit out with her hand especially. This horrified her. It wasn't the sort of thing she would do. In fact quite the opposite. But as she talked of this, the symptoms receded. It came back and then receded again as the session 
went on. As Cordelia felt her anger, or sadness, the symptoms would diminish, and then she would talk of other things, the affect would disappear, and the pains and contracture would partially return. We were led to talk of her anger at me, as well as at her father, for not paying attention to her after her mother's death. Then, of her lying in the hospital bed, beside but facing away from her mother, on the same side as her pains now were, when she visited her mother in the last weeks of her life. She remembered little from the months after the fateful night where her father had made his announcement, but she did remember, she said, that she kept going to her father's bed at night and lying with him for comfort, on her side, cuddled up to him. When she left after that session what we had been talking of kept going through her mind, and over that day the physical symptoms cleared up completely.

\section{Second Patient: Joyce}

Joyce was a number of years into an analysis with me, during which we had dealt with sexual abuse from her childhood and relationship difficulties in her adult life. She had always remembered a time when she was travelling as a young adult, and had visited the house of an older and very successful colleague, in order to follow up on a position that he may have been able to offer her. She had said previously that he had made a sexual advance on her, cornering her in his back yard. She had run away, and never contacted him again -in fact had gone directly back home, which was quite a long trip from where she was. She had passed over this time rather quickly when it came up, being vague about what had happened, and generally avoided talking about it. But at this point in the therapy, we had been led back to that time by certain reactions of Joyce's in the present day, as well as discrepancies in her story, especially related to the timing of events and when she came back. She herself seemed driven to make sense of what had happened, but then as she approached it would find herself backing off and avoiding the topic.

I pointed out to Joyce that as she brought up this incident she started saying, "I don't know", at the end of almost every sentence. This proclamation had been much in evidence as we approached the most overwhelming part of Joyce's earlier childhood traumas of sexual abuse, and the statement increased in frequency as we came closer to those core memories. I have observed this particular statement, and other repeated ones such as "maybe", in similar circumstances in many patients, and see it as a form of denial with regard to these traumatic memories: an energetic turning away from what is seen.

I said that her saying "I don't know" might be an indication that something further had happened. Over a number of sessions we established that this man had put his hand on her knee and then had invited her to walk in his garden.

"So what happened then?" I asked.

"I just remember running away."

"So he must have tried something further."

"Maybe. I don't know. I just don't know."

"Well, see what you think of. Remember how in looking at the abuse by (her abuser in childhood) it seemed you didn't remember anything, but as you paid attention to it, more and more came up?"

A look of what seemed like a mixture of anger and anxiety passed over Joyce's face. "Nooo, Nooo" she said, combining the word no and a moan in one utterance.

"You look upset."

'I feel you're pushing me. You're pulling me into this, into looking at this, but it's not good."

Previously, when we were looking at her childhood abuse, Joyce had said she felt I was "bothering" her with questions and interpretations. We had traced this back to her feeling of being "bothered" by her abuser. As we talked at this later point about the incident with the colleague she complained a number of times about me and others "pulling" her into things.

Over the next few weeks Joyce developed bronchitis-like symptoms and a feeling that she was having trouble breathing. In one session I said "I wonder if he grabbed you and pulled you?"

"No. I don't know!"

"But if we look at your reactions, it might be that he grabbed you in the garden as you tried to run away. You said he was a very big man. Maybe he was on top of you and you could not breath."

"I am feeling the weight of him on me. But I don't see him."

"What do you see?"

"Nooo, Nooo." Joyce moaned. You're pulling me and pushing me now. Its not good."

"So it feels like its now?"

"It is now. You're just pushing me too hard and I can't breath. There's a burning in my throat. It hurts a lot."

"Did he perhaps grab your throat? Or perhaps force oral sex on you?"

"No. I know that wasn't it."

"So he probably grabbed you and pulled you. Then what?"

"The grass was soft on my back. I just said that. I don't know really. How do I know?"

"Well, you just said it was soft on your back. Maybe in the end you were on your back. What did you see?"

"I didn't see him. I didn't see anyone."

"But if you felt the soft grass, you must have been on your back, so he must have caught you."

'Noooo, Nooo. I don't know. You're pushing me too. I feel 
I can't breath. I see the sky and the flowers, that's all. Its all very quiet." Joyce said all this in a quite angry tone.

The analysis of this incident took a number of months and involved the analysis also of the repression of the time after, when Joyce was in a daze. On first analysis, we thought this was a single incident of rape, from which she had run away.

What emerged turned out only to be the leading edge of something even worse, and also somewhat different from what we first thought. Joyce had in fact been drugged and raped, but was then held hostage by a number of men for many weeks before she had finally escaped. The memories of Joyce's rape that I have just described were complicated by the fact that they also expressed repressed memories of the captivity in hidden form. Presenting them may also be complicated by the fact that in this sequence I was pushing Joyce towards the reliving quite forcefully at times, and this maybe seen as both possibly inducing the memories and as very bad technique. In relation to these concerns I will mention that Joyce had been in analysis for 7 years at the time of this interchange, that she had shown a very good ability to stabilize after strong relivings, and that her analysis continued quite well following this session. Which is not to say that I wasn't taking part in an enactment to some extent, but it was not one that hurt the therapy. In any case I present this material not as an example of how to handle trauma technically, but because it displays so vividly the nature of post traumatic memories and mental functioning, which I have designated as the zero process.

\section{Traumatic Memories}

The characteristics of the sort of reliving displayed by Joyce are well known and well described by those who work with trauma and by those people who have suffered from it. The memory behaves more like a perception or immediate experience. It has the sensory intensity of experience, but also the lack of any distance between the observer and the memory. The pieces of experience as they occur are also not well integrated into a linear narrative. For Joyce the feel of the grass on her back, the weight of the man on top of her making it hard to breathe, the sight of the sky and flowers, and the extreme fear were all felt in their full immediacy, but all somewhat separate from each other. In fact they were more intense than what a regular perception or experience maybe. There are many reasons for this. One that was important in this case, and quite common generally, was the fact, mentioned already, that the memory served to screen even more deeply repressed traumatic memories. Leaving screening on one side, other factors leading to the intensity of the reliving included of course the intensity of the original experience it- self, but also the shutting down of a number of ego functions, especially abstraction, verbalization, and integration, during the trauma. This has been well understood by many trauma theorists: that the lack of processing of the original experience is what leads to its intensity and staying power. But it is worth noting that processing is a general term, which covers many different mental actions. These different actions also have a hierarchical and sequential aspect. By which I mean that certain actions have to be performed before other functions can be brought to bear on the experience. An example relevant to trauma is that adding symbolic language, relation to the self, and a narrative to memories of an event are later stage actions. A good deal of processing, a good number of different mental actions, have to be performed before you have a set of memories that have even the possibility of being connected to language and a narrative. These actions are usually performed so quickly in regular experience that we do not notice them, and we assume that the end product of these actions is direct, unmediated experience, which can then be connected to words and become an autobiographical memory. I would propose to refer to the summation of these basic mental actions as the first order construction of the present moment or of present experience. Trauma exposes the existence of this first order construction by interfering with it and, in extreme cases, shutting it down almost completely.

Normally we sample a small amount of the incoming perceptual stimuli, comparing it to our expectations and models of the world, to construct our experience. This all takes place below the threshold of awareness. Integration of different sensory modalities and pieces of experience across time is an example of this sub threshold activity. We see the lack of it in Joyce's bits and pieces of experience as they emerged from repression in the sessions described. Not so often commented upon, but also important, is the work of differentiation. Our immediate present experience is a product of the subtle and ongoing, but completely unrecognized and taken for granted, interplay between integration and differentiation. When these processes are deficient, experience takes on strange qualities, of fragmentation but also of lack of the usual boundaries between self, other, and various aspects of perception. In abuse and even in natural disaster traumas, the person traumatized feels fused with the traumatizing person or natural forces. Taking this fusion and identification with the aggressor into account is important in therapy.

Of the functions that fail during the traumatic process one of the most consequential is a superordinate one, which Hartmann (1950) called the organizing function. While it's name may give the impression of something highly intellectual, it proceeds much more quickly than conscious thought or the intellectual functions. Its work is to give each function it's place 
and importance in a fast, dynamic, and flexible manner. A well running organizing function would be able to put thought aside in many areas so that automatized and rote functions, which are much more efficient, can manage things, calling up consciousness and thought only when useful. This organization and ordering of various functions breaks down during trauma. A number of other mental actions are also impaired or completely shut down during the traumatic process, among them abstraction and the linking of the perception to previous ones and to the person's models of the world more generally. But if this was all that occurred in trauma, then we would have memories that were fragmented, unorganized, overly concrete, and not well put together in other ways. They would still behave like regular memories-they could be retrieved, and would tell a rather strange and imperfect tale of what had happened, reflecting the person's mental state during the trauma. What actually transpires is quite differentand decisive. While what is left after trauma behave like memories in the sense that they are retained over time, in most other ways they behave much more like present experiences. Joyce did not remember her rape in the usual way, she lived it as a present experience. Once the experience was set going, she could not control it. She could not for instance stop it, and look back at some earlier part of it she had just thought of, as she would have done with a regular memory, even a memory of a terrifying incident. I first gave the name zero process to this type of post traumatic functioning in my book on defences (Fernando 2009). I decided on the term zero process because this connected it with the primary and secondary processes, as one of the three great regions of the mind, or ways in which the mind functions. I felt the name also suggested more of an addition, rather than a replacement, of what had been discovered about the primary process in development and in neurosis by Freud and other analysts.

It has been evident since the beginning of scientific work on trauma that traumatic memories behave very much like experiences. However, in thinking of the zero process, it has only dawned on me slowly just how important it is to think of post traumatic functioning not just as memories that are very intense and thus mimic experiences, but rather to understand that the core of post traumatic functioning really is, at the psychical level, not a set of memories at all. They have the characteristic of memory of being retained over time, but in other ways they behave like an experience. Or, more accurately, something like Joyce's reactions are not regular experiences, they are a kind of raw, only partially processed, experience. More than this, they are experience before it has happened, stopped short in the middle of its construction by the traumatic process. By using our understanding of the traumatic process, as something that leads to the shutting down of ego actions involved in the first order construction of experience, we can make sense of the seemingly senseless idea of a memory/experience that has not yet happened. Because the bits and pieces of these zero process memories, for instance Joyce's memories of her rape, have not been used to construct the experience, we can quite rightly say that, at the psychical level, the experience has not yet happened, in the usual meaning of an experience that has happened to us and can then be remembered. What Joyce had were zero process proto-memories: such stuff as not only dreams and memories, but experience itself, are made on. Her experience of the trauma had not yet been fully made. It existed as a potential, and in that sense it was still in the future, although when triggered portions of the traumatic memory would play out as an immediate present experience. Conceptualizing the nature of the zero process as a present/future experience, about to happen, at times happening, but never happening fully enough to be encoded into more regular long term memory, can seem at first enigmatic. But it is an enigma that, if unravelled and properly understood conceptually leads to the unravelling of many of the other enigmas surrounding trauma.

Joyce's dramatic reliving is only one way in which the zero process expresses itself. It lives as another reality, a reality that is always about to happen, or happening. As a more common example, we can take Cordelia's reaction when someone was sick, of pushing all sorts of remedies on them, and getting angry at them for not being more active in attending to their health and following her advice. This type of pushiness was not a general character trait of hers. Rather, it was informed by the other reality, a zero process reality, that had existed for her since she had been told of her mother's death. In this reality the person was about to die and regular medicine and regular treatments were not going to work, just as they hadn't worked for Cordelia's mother. Quick action and desperate measures had to be taken, as it was a life and death situation. Also, Cordelia was angry at this dying person for not taking care of themselves and for leaving her all alone. A number of Cordelia's other reactions, for instance her stomach pains, loss of appetite and loss of weight, also related to this other reality. This is how the zero process usually presents: as sets of physical and mental reactions which are thought by the person and those around them to relate to the present reality, but which are actually an expression of the unprocessed traumatic one. A dramatic example was presented by William Niederland (1981) in his description of a former inmate of a Nazi death camp: "one of my survivor patients told me that at the time of liberation from the concentration camp his weight was down to $94 \mathrm{lbs}$. and he looked like a "plucked chicken." Though he is now of normal weight and appearance, he cannot be sure-he told me-that he has not the 
looks of a plucked chicken still today, and with great regularity he refuses to leave his home, in order not to be seen by other people (p. 417)." Another of Niederland's (1965) patients had been diagnosed as schizophrenic because he seemed to have the delusion of freezing, even in hot weather, and would dress in layers of clothing, and shiver in the office while wearing a winter coat. Other aspects of his interactions in the therapy did not seem schizophrenic to Niederland and as he stuck with him in therapy the patient began to thaw out and not feel so cold. A dream depicted him near or at the North Pole, his bed a block of ice or a refrigerator, surrounded by the ice, cold, and darkness of a seemingly endless night. When dawn finally came, some people walked in and out of the room where he lay. Niederland was led to ask his patient, in analyzing this dream, if he had ever actually had an episode of freezing. The patient asked his parents, who were surprised, and said they had left the window open on a very cold day in his bedroom, and he had almost frozen to death, and had to be thawed out. He was taken to hospital, where he acquired a pneumonia and took quite a while to recover. This had happened when he was less than a year old. Upon the patient hearing of this episode, the therapeutic outcome was immediate, and sustained, without any of the seeming psychosis coming back.

This clinical material presented by Niederland quite dramatically brings out the immediate reality of the zero process, to the point where it can appear psychotic. Joyce also appeared to lose touch with reality when under the spell of her traumatic memories. Unlike a true psychosis, however, in these situations the loss of reality contact is based on the switch to the other, traumatic, reality, while in schizophrenia or other psychosis there is a broader loss of the basic functions that maintain contact with reality.
In this paper I have presented some basic ideas about the nature of the traumatic process and of the zero process memories it leaves in its wake, giving some detailed clinical material to serve as illustration. I have tried to show how the traumatic process of a shut down of higher level ego functions leads to the formation of a different form of mental functioning, the zero process, which is retained over time and in that sense is a memory, but in many other ways behaves much more like a lived present experience. In the second paper of this series, "Trauma and the zero process: theoretical considerations", I will delve further into the implications and applications of the idea of the zero process.

\section{Acknowledgments}

This article was presented during 'Seminars with Dr. Fernando on trauma' with KAPA on 16-19 March, 2018.

\section{Conflicts of Interest}

The author has no financial conflicts of interest.

\section{REFERENCES}

Breuer J, Freud S. Studies on hysteria. SE 2. London: Hogarth Press; 1895. Fernando J. The processes of defense: trauma, drives, and reality $-\mathrm{A}$ new synthesis. Lanham, Md: Jason Aronson;2009.

Freud S. Beyond the pleasure principle. SE 18. London: Hogarth Press; 1920. p.1-64.

Hartmann H. Comments on the psychoanalytic theory of the ego. Psychoanal Study Child 1950;5:74-96.

Niederland WG. The role of the ego in the recovery of early memories. Psychoanal Q 1965;34:564-571.

Niederland WG. The survivor syndrome: further observations and dimensions. J Am Psychoanal Assoc 1981;29:413-425.

Van Der Kolk BA, Van Der Hart O. The intrusive past: the flexibility of memory and the engraving of trauma. In: Caruth C. Trauma: explorations in memory. Baltimore, MD: Johns Hopkins University Press;1995. p.158-182. 